\title{
POTENSI HASIL PRODUK BLEAGIBERRY (BLEACHING GIGI EKSTRAK BUAH STRAWBERRY)
}

\author{
Saelin Nikhla \\ Akuntansi, Fakultas Ekonomi dan Bisnis, Universitas Muhammadiyah \\ Purwokerto \\ Email : $\underline{\text { saelinnikhla@gmail.com }}$ \\ Afik Nuraeni \\ Akuntansi, Fakultas Ekonomi dan Bisnis, Universitas Muhammadiyah \\ Purwokerto \\ Email :afiknuraeni@gmail.com \\ Ulfatunnisa Fauziyah \\ Farmasi, Fakultas Farmasi, Universitas Muhammadiyah Purwokerto \\ Email :ulfatunnisaf@gmail.com
}

\begin{abstract}
ABSTRAK
Buah strawberry sudah lama diketahui memiliki banyak khasiat. Selain diambil sarinya, buah strawberry baik untuk memutihkan gigi (Bararah, 2009). Strawberry merupakan sumber yang kaya akan vitamin $\mathrm{C}$ dan beberapa senyawa antioksidan lainnya. Buah dan daun strawberry berkhasiat sebagai pemutih kulit alami, pemutih email gigi serta mencegah penumpukan karang gigi. Penelitian ini bertujuan untuk mengetahui keunggulan produk BLEAGIBERRY dan potensi hasil yang didapatkan dalam usaha BLEAGIBERRY. Metode yang digunakan ada 5 yaitu pencarian bahan baku dan alat yang pendukung, pelaksanaan produksi, pengujian produk, pembuatan kemasan dan pemasaran. Hasil yang dicapai dari produksi BLEAGIBERRY yaitu laba per produk sebesar 107\% dari HPP. Sedangkan untuk BEP produk yaitu total penjualan sebesar 12.500.000, BEP unit sejumlah 50 unit, BEP rupiah sebesarRp 5.732.809 dan Payback period selama
\end{abstract} 20 bulan.

Kata kunci: strawberry, BLEAGIBERRY dan BEP (Break Event Point) 


\begin{abstract}
Strawberry fruit has long been known to have many benefits. In addition to the juice, strawberries are good for whitening teeth (Bararah, 2009). Strawberry is a rich source of vitamin $C$ and some other antioxidant compounds. Strawberry fruit and leaves nutritious as natural skin whitening, tooth enamel whitening and prevent the buildup of tartar. This study aims to determine the benefits of BLEAGIBERRY products and the potential results obtained in the business BLEAGIBERRY. The methods used are 5 searching for raw materials and supporting tools, production implementation, product testing, packaging and marketing. The results achieved from BLEAGIBERRY production are earnings per product of $107 \%$ of HPP. Whereas for BEP products are total sales of 12,500,000, BEP units of 50 units, BEP rupiahs of Rp 5,732,809 and Payback periods for 20 months.
\end{abstract}

Keywords: strawberry, BLEAGIBERRY and BEP (Break Event Point)

\title{
PENDAHULUAN
}

Bleaching yaitu suatu proses untuk mengurangi warna gigi melalui agen kimia untuk mengoksidasi pigmentasi organik (Jacob et al., 2007). Bahan yang digunakan untuk bleaching pada umumnya adalah hidrogen peroksida atau karbamid peroksida. Tidak hanya pada gigi, bahan bleaching juga dapat diaplikasikan pada permukaan restorasi estetik. Hasil penelitian Pruthi et al (2010) menunjukkan aplikasi karbamid peroksida pada permukaan resin komposit dan GIC (Glass Ionomer Cement) menimbulkan peningkatan kecerahan yang signifikan pada warna restorasi. Aplikasi karbamid peroksida $10 \%$ telah diteliti mampu menghilangkan stain pada permukaan restorasi resin komposit melalui reaksi oksidasi.

Adapun pemutihan gigi memiliki keuntungan dan kerugian dalam penggunaannya. Keuntungan dalam pemutihan gigi yaitu: gigi yang gelap atau kusam dapat dibersihkan dalam waktu yang relatif singkat (dari 4-5 hari hingga 3 atau 4 minggu); meningkatkan rasa kepercayaan diri dan tingkat keputihan gigi dapat dikontrol. Kerugian dalam pemutihan gigi yaitu: pemakaian zat pemutih (bleaching trays) menyebabkan terganggunya pencernaan dan berubahnya persepsi rasa yang diakibatkan oleh bahan kimia yang digunakan dalam proses pemutihan gigi; hipersensitivitas gigi; iritasi pada gusi; sakit tenggorokan; kesulitan untuk menggigit dan menimbulkan kecanduan atau ketagihan (Wahyuningsih, 2010). 
Penggunaan bahan alam saat ini menjadi sangat populer, karena pertimbangan keamanan, murah dan lebih mudah didapat. Penelitian dengan memanfaatkan bahan alam banyak dilakukan karena hal ini dianggap sangat bermanfaat di mana sejak dahulu masyarakat kita telah percaya bahwa bahan alam mampu mengobati berbagai macam penyakit dan jarang menimbulkan efek samping yang merugikan dibandingkan obat yang terbuat dari bahan sintetik (Purnamasari dkk., 2010). Berbagai macam bahan alami dapat digunakan sebagai alternatif material bleaching, salah satunya adalah dengan menggunakan strawberry.

Buah strawberry sudah lama diketahui memiliki banyak khasiat. Selain diambil sarinya, buah strawberry baik untuk memutihkan gigi (Bararah, 2009). Strawberry merupakan sumber yang kaya akan vitamin $\mathrm{C}$ dan beberapa senyawa antioksidan lainnya. Buah dan daun strawberry berkhasiat sebagai pemutih kulit alami, pemutih email gigi serta mencegah penumpukan karang gigi. Strawberry dapat memutihkan kembali gigi yang telah berubah warna, karena mengandung asam elegat (ellagic acid) dan asam malat (malic acid) yang dapat memutihkan gigi. Asam malat merupakan golongan asam karbosilat yang mempunyai kemampuan memutihkan gigi dengan mengoksidadi permukaan email gigi sehingga menjadi netral dan menimbulkan efek pemutihan (Asmawati, Aulia, 2016). Popularitas strawberry sebagai tanaman buah terutama menghasilkan aroma yang unik, rasa manis, warna cerah, dan memiliki nilai gizi. Kualitas tersebut sangat ditentukan oleh komposisi metabolisme dari buah (Asmawati, 2016).

Penelitian sebelumnya telah membuktikan adanya efektivitas jus buah stroberi sebagai bahan pemutih gigi alami secara in vitro dengan metode perendaman selama 1 jam, 3 jam, dan 5 jam, namun hasil penelitian menunjukkan $\mathrm{pH}$ dari larutan buah strawberry yaitu 4,3 dianggap terlalu asam. Kondisi ini memicu terjadinya demineralisasi enamel sehingga menurunkan kekerasan permukaan enamel.Dengan demikian diperlukan pengembanganstrawberrydalam sediaan yang lebih aplikatif, yaitu dalam bentuk sediaan gel.

Usaha BLEAGIBERRY (bleaching gigi ekstrak buah strawberry) ini sangat potensial dan memiliki prospek pengembangan yang positif. Sejauh ini belum ada produsen yang mengembangkan pembuatan bleaching dari buah strawberry yang memiliki konsep yang sama dengan produk ini. Peluang ini juga didukung oleh ketersediaan bahan baku di Purbalingga yang melimpah sehingga kontinuitas dari produk dapat terjaga. Ide pengembangan produk ini juga bermanfaat untuk meningkatkan pendapatan daerah menyerap tenaga kerja dan mengurangi pengangguran apabila dikembangkan dalam skala besar. Maka dari itu perlu didirikannya usaha BLEAGIBERRY (bleaching gigi ekstrak buah strawberry) semacam ini. 


\section{METODE}

\section{Modal}

Modal usaha ini berasal dari modal yang didanai atau diinvestasikan oleh DIKTI, di mana modalnya disesuaikan dengan pengajuan proposal sebesar Rp 8.000.000.

\section{Waktu dan Tempat}

Adapun waktu dalam pelaksaan kegiatan itu sendiri adalah dimulai dari akhir bulan April yaitu dengan membeli bahan baku berupa strawberry, membuat ekstrak etanol, mencari sampel gigi sapi, membeli bahan habis pakai lainnya, melakukan optimasi formula, dan melakukan uji stabilitas. Kemudian dilanjutkan pada bulan ke-2 melanjutan uji stabilitas, membuat desain kemasan, melakukan uji khasiat gel, mencetak kemasan, membuka sistem Pre Order dan promosi, dan membuat produk BLEAGIBERRY yang akan dijual. Selanjutnya pada bulan ke-3 diisi dengan berbagai kegiatan seperti melakukan promosi, membuat media sosial untuk promosi, membuat brosur, melakukan penjualan, membuat laporan kemajuan, dan membuat artikel ilmiah.

Lokasi yang akan digunakan untuk memproduksi BLEAGIBERRY ini dilakukan di Laboratorium Fakultas Farmasi Universitas Muhammadiyah Purwokerto.

\section{Tahapan Pelaksanaan}

\section{a. Pencarian bahan baku dan pembelian alat-alat pendukung produksi}

Dilakukan pembelian alat-alat produksi dan pencarian bahan baku yaitu buah strawberry yang dapat dicari dilingkungan sekitar kebun strawberry yang ada di Desa Serang, Kecamatan Karangreja, Kabupaten Purbalingga.

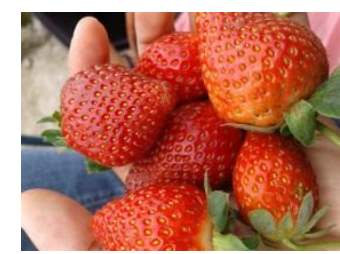

\section{Gambar 1. Buah Strawberry}

\section{b. Pelaksanaan Produksi}

Jumlah produk yang diproduksi adalah 750 gram dalam 3 bulan.Alat yang dibutuhkan untuk membuat produk ini yaitu : mortir, stamper, kamera, alat-alat gelas dan shade guide.Sedangkan bahan yang digunakan adalah buah strawberry, Etanol 95\%, Bais gel dan Sediaan toothbleaching. 

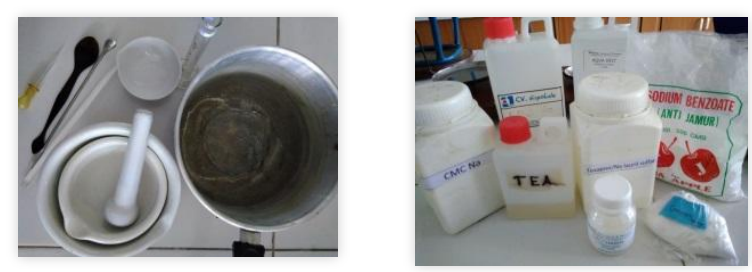

\section{Gambar 2. Alat dan Bahan}

Cara Pembuatan :

1. Pembuatan gel diawali dengan melarutkan CMC Na dan Carbopol 940 dalam $50 \mathrm{~mL}$ aquadest dengan pengadukan yang terus menerus (larutan 1).

2. Selanjutnya $5 \mathrm{~mL}$ aquadest digunakan untuk melarutkan $\mathrm{Na}$ benzoat dengan pemanasan menggunakan water bath (larutan 2).

3. Setelah larutan dingin masukkan PEG 400 ke dalam larutan kedua. Larutkan $\mathrm{Na}$ saccharin dan $\mathrm{Na}$ lauril sulfat dan selanjutnya di campurkan ke larutan sebelumnya.

4. Setelah itu, menambahkan ekstrak Strawberry dengan penambahan aquadest. Terakhir tambahkan semua bahan yang dicampur dengan carbopol (larutan 1) dengan pengadukan terus menerus dengan penambahan trietanolamin. Penambahan trietanolamin ini harus hati hati untuk mendapatkan $\mathrm{pH}$ antara 6,8-7 dan aduk sampai konsistensi gel yang diinginkan.
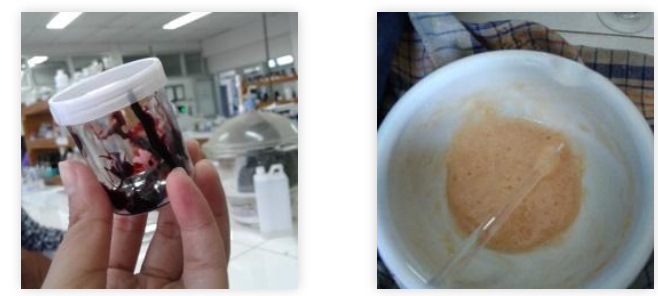

\section{Gambar 3. Ekstrak Strawberry dan Hasil Akhir Gel}

\section{c. Pengujian Produk}

Terdapat 2 macam pengujian yang dilakukan yaitu :

1. Uji Stabilitas : Uji Freeze-thaw cycling dilakukan untuk melihat pengaruh suhu terhadap gel selama penyimpanan pada dua suhu yang berbeda, yaitu pada kondisi beku (freeze) pada suhu $4^{\circ} \mathrm{C}$ dan meleleh pada suhu $45^{\circ} \mathrm{C}$ (Warnida et al., 2016) 

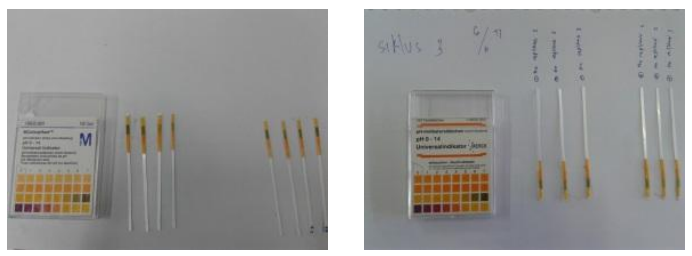

Gambar 4. Uji Stabilitas

2. Uji Khasiat : untuk mengetahui potensi sediaan gel yang dibuat dalam memutihkan gigi. Gel diaplikasikan ke gigi setiap hari selama 12 hari, setiap 8 jam selama 5 menit aplikasi
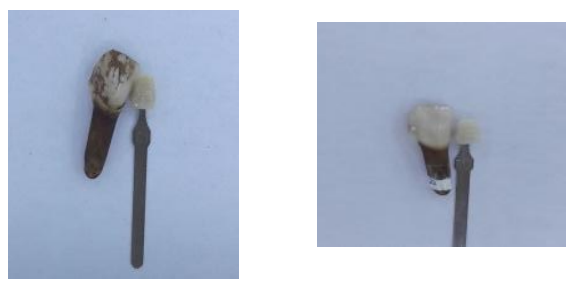

\section{Gambar 5. Uji Khasiat}

\section{d. Pembuatan Desain Kemasan}

Setelah produk BLEAGIBERRY dihasilkan, perlu penanganan selanjutnya agar BLEAGIBERRY tersebut terjual dipasaran yaitu pengemasan. Kemasan merupakan salah satu daya tarik bagi konsumen untuk membeli produk BLEAGIBERRY. Dalam proses pengemasan BLEAGIBERRY dikemas dalam pot salep dengan ukuran 30 gram.

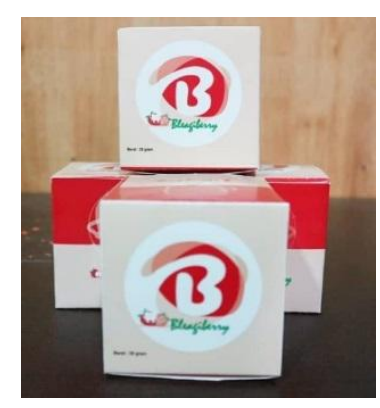

\section{Gambar 6. Kemasan}

\section{e. Pemasaran}

Proses pemasaran yang kami lakukan yaitu dengan cara mempromosikan dan pemasaran langsung kepada konsumen serta secara online.Via online meliputi penggunaan sosial media: 

1. Facebook
: Bleagiberry_ump
2. Instagram
: @Bleagiberry

\section{HASIL DAN PEMBAHASAN}

\section{Laba per Produk}

Harga promosi per produk $\quad$ : Rp. 50.000

Biaya produksi + operasional : Rp. 24.130

Laba per produk

: Rp. $25.870(107 \%)$

\section{Realisasi Penjualan}

\begin{tabular}{ccc}
\multicolumn{3}{c}{ Tabel 1.Realisasi Penjualan } \\
\hline Bulan & Penjualan & Laba \\
\hline Juni & 10 & 258.700 \\
Juli & 6 & 155.220 \\
Total & 16 & 413.920 \\
\hline
\end{tabular}

\section{Break Event Point}
a. Total Penjualan
$=250$ unit $x \operatorname{Rp} 50.000=\operatorname{Rp} 12.500 .000$
b. BEP Unit
$=\quad$ Biaya tetap
(Harga per unit - Biaya Variable per
Unit)
$=\quad \operatorname{Rp} 1.967 .500$
$(\operatorname{Rp} 50.000-\operatorname{Rp} 11.330)$
$=50$ unit 
c. BEP Rupiah

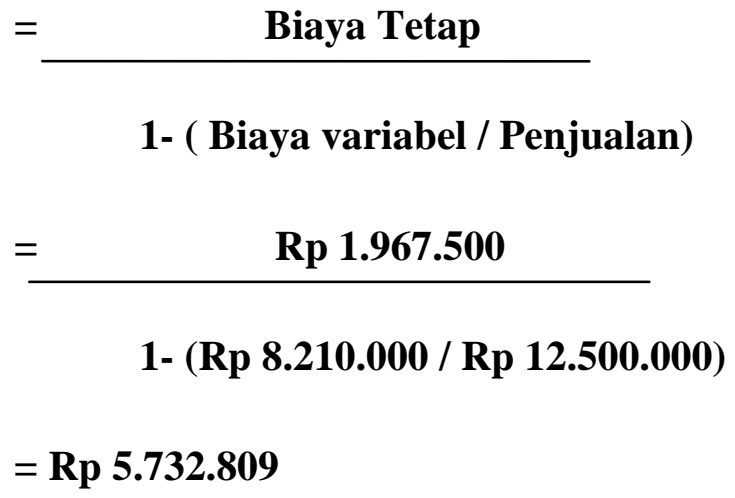

1- ( Biaya variabel / Penjualan)

$=\quad \operatorname{Rp} 1.967 .500$

1- (Rp 8.210.000 / Rp 12.500.000)

$=\mathbf{R p} 5.732 .809$

- Payback Period = Jumlah investasi awal / Laba per bulan

$=\operatorname{Rp} 8.000 .000 / \operatorname{Rp} 413.920$

$=20$ bulan

\section{KESIMPULAN}

Penggunaan strawberry sebagai bahan alami pemutih gigi merupakan solusi terbaik dibandingkan dengan pemutih gigi berbahan sintesis. Kandungan buah strawberry yang kaya akan vitamin $\mathrm{C}$ dan beberapa senyawa antioksida dan lainnya dapat memutihkan kembali gigi yang telah berubah warna. Pengembangan strawberry dalam sediaan sediaan gel dapat lebih aplikatif dalam penggunaannya. Metode yang digunakan yang pertama yaitu pencarian bahan baku dan pembelian alat-alat pendukung, kedua yaitu pelaksanaan produksi, ketiga yaitu pengujian produk, keempat yaitu pembuatan kemasan dan terkahir yaitu pemasaran produk. Hasil yang dicapai dari produksi BLEAGIBERRY yaitu laba per produk sebesar 107\% dari HPP, Laba penjualan selama 2 bulan sebesar Rp 413.920. Sedangkan untuk BEP produk yaitu total penjulan sebesar 12.500.000, BEP unit sejumlah 50 unit, BEP rupiah sebesarRp 5.732.809 dan Payback period selama 20 bulan. Melihat dari data tersebut hal ini bisa Usaha BLEAGIBERRY (bleaching gigi ekstrak buah strawberry) sangat potensial dan memiliki prospek pengembangan yang positif.

\section{DAFTAR PUSTAKA}

Asmawati, Musidiyah Aulia. 2016. Pemanfaatan Buah Strawberry sebagai Bahan Pemutih Gigi.Makasar Dent J 2016; 5(2): 40-43.

Bararah, V. F. 2009. Gigi Putih dengan Ampas

Strawberry.(http://health.detik.com diakse pada 15 Oktober 2017).

Ester, M. 2005. Bahaya Bahan Kimia pada Kesehatan Manusia dan Lingkungan.

EGC: Jakarta. 
Hartanto, A. 2011. Aplikasi Pasta Buah Stroberi terhadap Perubahan Warna dan Kekerasan Permukaan Enamel. Universitas Airlangga: Surabaya.

Fejerskov O, Kidd E. Dental caries: the disease and its clinical managemen. Oxford: Blackwell Munksgaard Ltd,:2009.p444

Agustina A, Sutaryono, Nisa AK. Formulasi gel ekstrak buah strawberry (Fragaria Sp,) dengan gelling agent karbomer. Motorik 2013 Agt; 8(17): 14-22

Ansel CH, Allen LV. Ansel's pharmaceutical dosage forms and drug delivery systems. $10^{\text {th }}$ ed. Philadelphia: Wolters kluwer; 2014. p323-4 